\title{
Measures of EEG and verbal intelligence: An inverse relationship*
}

\author{
J. D. EVERHART, C. L. CHINA, and R. A. AUGER \\ Veterans Administration Hospital, Salisbury, North Carolina 28144
}

\begin{abstract}
An inverse relationship exists between WAIS verbal IQ scores and measures obtained from a commercial EEG device, the neural efficiency analyzer. It is concluded that the relationship is one between psychometric verbal intelligence and spontaneous ongoing EEG frequency. The amount of variance accounted for by the correlation is too small, however, to warrant use of the instrument as a predictor of psychometric intelligence.
\end{abstract}

Since Caton (1875) reported that he had detected electrical currents picked up by electrodes placed on the scalp of laboratory animals, investigators have attempted to demonstrate that variations in EEG signals reflect processes which are related to a wide variety of behavioral phenomena (Kiloh \& Osselton, 1971). In recent years the question concerning the relationship between human intelligence and electrophysiological correlates has generated widespread public and scientific interest (Perry \& Childers, 1969). However, data reported to date are inconclusive and fall far short of providing the necessary documentation for the existence of meaningful electrophysiological analogues of human intelligence (Asher, 1973; Barry \& Ertl, 1965; Chalke \& Ertl, 1965; Ellingson, 1966; Plum, 1968; Regan, 1972; Rhodes, Dustman, \& Beck, 1969; Shagass, Haseth, Callaway, \& Jones, 1968; Shucard, 1969; Shucard \& Horn, 1972; Vogel, Broverman, \& Klaiber, 1968; Weinberg, 1969).

Generally, the literature suggests that individuals who score higher (relative to lower) on standard psychometric tests of intelligence will generate shorter latencies of major VER components. However, this statement is true only over a wide range of test score differences (i.e., 20 to 30 points) (Perry \& Childers, 1969). Even though correlations are statistically significant, precise individual predictions cannot be supported. The relationship between VER latency and psychometric intelligence test scores is supportive of the assumption that the economic efficiency of information processing of individuals scoring higher on standard psychometric tests of intelligence would be reflected in faster processing time (i.e., shorter latencies). However, this assumption has only partial face validity. There is a tendency for VERs to become increasingly complex in wave form (i.e., the number of components increase) as higher scoring Ss are tested (Perry \& Childers, 1969). The difficulty in isolating and measuring latencies across VERs of different waveforms is amplified as the differential between the norm (IQ 100) and the higher

\footnotetext{
*R equests for reprints should be sent to $J$. Don Everhart, PhD, Consulting Psychologist, P. O. Box 5549, Greensboro, North Carolina 27403.
}

scores. The identification of homogeneous waveform components for comparison is only one of the evident problems.

Vaughan, in Kietzman et al (in press), has criticized many of the attempts to relate psychometric intelligence to some feature of VERs on the grounds that they are based on nothing more substantial than the fact that brain processes underlie both phenomena, psychometric intelligence and VERs. Regan (1972) lends support to this point by stating that, to date, reported data can only suggest a relationship between psychometric intelligence (see p. 3) and VERs are not thought to be spurious, the possibility that only minimal information is given is great.

The only real dissension from the prevailing conclusion that meaningful neurophysiological predictors of individual intelligence have yet to be discovered comes from Ertl $(1968,1971)$. He describes a device of his own invention, the neural efficiency analyzer (NEA) which purportedly measures a "neural efficiency" factor related to intelligence. In view of the obvious importance to the scientific community of such a discovery, together with the lack of validating studies by other investigators, it seemed worthwhile to conduct our own independent study of the instrument.

The three studies herein described were addressed to two primary questions: (1) Does the NEA measure VEPs? (2) What is the nature of the relationship between NEA scores and psychometric intelligence? Experiment I attempted to answer Question 1. Experiments II and III were addressed to Question 2. Experimental procedure, results, and conclusions are summarized for each study separately; integration is accomplished in the discussion.

Preliminary to the studies, a Model NEA-100P neural efficiency analyzer was leased from Neurometrics, Inc., an affiliate of Associates International, Inc. The instrument package consisted of the following: (a) scalp electrodes, (b) an EEG preamp, (c) a low-intensity "strobe"-type photic stimulator, (d) the NEA computer unit, and (e) a small monitor oscilloscope. Two nixie tube readouts, labeled $\mathrm{A}$ and $\mathrm{B}$, were provided on the computer unit. Readout A constituted the primary neural efficiency score; Readout B was purportedly a 
Table 1

Mean NEA Scores Over Six Trials for Three Male and Three Female Subjects

\begin{tabular}{rcrrrrrrr}
\hline $\mathrm{S}$ & $\mathrm{Sex}$ & $\mathrm{T}_{1}$ & $\mathrm{~T}_{2}$ & $\mathrm{~T}_{3}$ & $\mathrm{~T}_{4}$ & $\mathrm{~T}_{5}$ & $\mathrm{~T}_{6}$ & Mean \\
\hline 1 & $\mathrm{~F}$ & 112 & 110 & 115 & 111 & 109 & 110 & 111 \\
2 & $\mathrm{M}$ & 146 & 145 & 149 & 143 & 143 & 144 & 145 \\
3 & $\mathrm{M}$ & 184 & 185 & 184 & 184 & 183 & 184 & 184 \\
4 & $\mathrm{~F}$ & 119 & 122 & 120 & 119 & 118 & 118 & 119 \\
5 & $\mathrm{M}$ & 150 & 150 & 150 & 151 & 150 & 150 & 150 \\
6 & $\mathrm{~F}$ & 101 & 98 & 99 & 102 & 103 & 98 & 100 \\
\hline
\end{tabular}

Note-Condition: eyes open, stimulus light on.

validity check on A. Operating instructions were furnished, as well as a lay description of what the apparatus was supposed to do, but both the inventor and the manufacturer refused to furnish a technical manual or simple block diagram of the NEA on the grounds that the electronics were classified and could not be released.

In order to establish the neuroelectric meaning of the readout scores, an analysis of the electronic circuitry logic was undertaken. A known signal was applied using a Hewlett Packard 3310A function generator coupled with a General Radio Company audio-frequency microvolter, Type 546-C, and a Tektronix dual beam oscilloscope, Model 5051. By varying the amplitude of the signal with a range of 6 to $30 \mathrm{microV}$ and the frequency between 1 and $40 \mathrm{~Hz}$ and recording the readout data, it became clear that the NEA was sensitive to frequency but only minimally sensitive to amplitude, if at all.

Further analysis indicated that the EEG preamp of the NEA was activated by a negative falling signal which, in turn, triggered a random time pulse generator in the NEA computer unit. The random time pulse generator activated the stimulus light with between-flash intervals varying from 400 to $1,600 \mathrm{msec}$. The light flash had a duration of $6 \mathrm{msec}$. The EEG signal was time-locked from the first falling zero crossing after termination of the flash to the second falling zero crossing (Readout A). In essence, Readout $\mathbf{A}$ scores represent the mean time (msec) interval between zero crossings, which dictates that the slower frequencies will be summed to a higher number (time/msec) value, while the faster frequencies sum to a lower one. Readout B scores reflect the EEG signal time-locked from the first falling zero crossing after termination of the flash to the third falling zero crossing. These data were noted but not preserved since their only function, as represented by the manufacturer, was the detection of unwanted artifacts (namely, muscle potentials) in Readout A. Zero crossing averaging was effected for 100 stimulus presentations. Logic dictated that if the NEA was sensitive only to frequency, it was not measuring VEPs.

Prior to any formal experimentation, it was noted that electrode placement as specified by the inventor (Ertl, 1968) failed to produce a consistent Readout A score (i.e., bipolar scalp-contact electrodes placed $6 \mathrm{~cm}$ apart over the right sensorimotor area, parallel with the midline and astride $\mathrm{C}_{4}$ in the 10-20 system and indifferent electrode to the right earlobe). Personal intercommunication with the manufacturer's chief engineer produced the suggestion that different sites be tried until a consistent reading was obtained. Following Plum (1968), a satisfactory electrode placement was developed, as outlined in a following section of this paper.

A pilot study, using three male and three female Ss not included in any of the subsequent experiments, was conducted in order to verify the reliability of obtaining consistent NEA scores on repeated measures. Experimental conditions were: eyes open and stimulus light on. Six trials were run for each S.

The analysis of the pilot study data was accomplished by simply computing the mean $\overline{\mathrm{X}}$ value for the six repeated trials. The data confirmed that a consistent score ( \pm 4 points) could be expected using the electrode placement outlined below (Plum, 1968).

It is of interest to note that female Ss, 1, 4, and 6, generated lower mean scores than male Ss, 2,3 , and 5 . This finding is consistent with other reports in the literature that females typically generate faster EEG frequencies than males (Perry \& Childers, 1969). Complete pilot data is reported in Table 1. The following study, designated Experiment I, was conducted as a test of the hypothesis that the NEA was sensitive only to frequency and was not measuring VEPs.

\section{EXPERIMENT I}

\section{Method}

Subjects. The Ss consisted of six hospital employees, three of whom were female internists in a dental assistants program. Their ages ranged from 18 to 25 years. Three Ss were male professional VA hospital employees whose ages ranged from 21 to 35 years. All Ss were volunteers, and no attempt was made to achieve variation in individual abilities.

Procedure. Each S was instructed to follow the directions of the E. The experimental apparatus was situated on a table directly in front of, and at eye level to, the $S$, at a distance of approximately 24 in. A block diagram modified from Perry and Childers (1969) was used to explain the procedure to each S.

After insuring that the $S$ understood the procedure and was relaxed and comfortable, silver-silver chloride bipolar scalp-contact electrodes were placed at $45 \mathrm{deg}$ from midline, $4 \mathrm{~cm}$ from $C_{2}$ between $C_{3}$ and $P_{z}$ and over $P_{3}$ in the 10-20 system (Plum, 1968). The ground electrode was placed on the left ear. Care was taken to insure that the resistance between the scalp recording electrodes was 10,000 ohms or less. Resistance was checked with a Simpson 260, Series 6, volt/ohm milliammeter. Ambient temperature was constant and illumination was maintained at a low level.

Each $\mathrm{S}$ was exposed to each of eight experimental conditions (see Table 2 for design schemata) which consisted of all possible combinations of (a) eyes open vs eyes closed, (b) attending to an auditory stimulus vs not attending to an auditory stimulus, and (c) having a flashing light stimulus presented vs not having a flashing light stimulus presented. The attending task consisted of pressing a switch to turn off a randomly scheduled (mean interval $10 \mathrm{sec}$ ) auditory signal produced by a Lehigh Valley 
Table 2

Mean Values for Each of the Eight Experimental Conditions in Experiment I

\begin{tabular}{|c|c|c|c|c|c|c|c|c|c|}
\hline \multirow{3}{*}{$\begin{array}{l}\text { Stimulus } \\
\text { Light } \\
\text { (C) }\end{array}$} & \multicolumn{3}{|r|}{$\begin{array}{l}\mathrm{b}_{0} \\
\text { Eyes }\end{array}$} & \multicolumn{2}{|l|}{$\begin{array}{l}\text { On } \\
\text { (A) }\end{array}$} & \multicolumn{4}{|c|}{$\begin{array}{ll}\mathrm{b}_{1} & \text { Off } \\
\text { Eyes } & \text { (B) }\end{array}$} \\
\hline & \multicolumn{2}{|c|}{$a_{0}$ Open } & & \multicolumn{2}{|c|}{$a_{1}$ Closed } & \multicolumn{2}{|c|}{$a_{0}$ Open } & \multicolumn{2}{|c|}{$a_{1}$ Closed } \\
\hline & Condition & Mean & & Condition & Mean & Condition & Mean & Condition & Mean \\
\hline $\begin{array}{l}\text { On } c_{0} \\
\text { Off } c_{1}\end{array}$ & $\begin{array}{l}1 \\
5\end{array}$ & $\begin{array}{l}119.33 \\
124.83\end{array}$ & & $\begin{array}{l}2 \\
6\end{array}$ & $\begin{array}{l}136.66 \\
138.66\end{array}$ & $\begin{array}{l}3 \\
7\end{array}$ & $\begin{array}{l}122.5 \\
119.00\end{array}$ & $\begin{array}{l}4 \\
8\end{array}$ & $\begin{array}{l}128.16 \\
136.57\end{array}$ \\
\hline
\end{tabular}

pocket programmer, Model LVE 558-53. The dependent variable was the average value of Readout A over three trials.

\section{Results and Conclusions}

Data generated in Experiment I were analyzed by two different methods. First, the mean values for each of the eight experimental conditions were computed. These values are presented in Table 2 . Note that the mean values in Conditions 2, 4, 6, and 8 are higher than the mean values for Conditions $1,3,5$, and 7 . Conditions 2 , 4, 6, and 8 represent the Ss' EEGs with eyes closed, while Conditions $1,3,5$, and 7 represent eyes open.

The EEG response of humans in the relaxed state, with eyes closed, is usually in the alpha range (e.g., $8-13 \mathrm{~Hz}$ ), the average being $10 \pm 1 / 2 \mathrm{~Hz}$ (Kiloh \& Osselton, 1961). The relaxed, eyes-closed condition seems to represent a form of sychronization. Cromwell et al (1973) have described this condition as the "natural" or "idling" frequency of the brain. As soon as the individual opens his eyes or becomes engaged in active cognitive processes, the slower alpha rhythms disappear and are replaced with a faster "dissynchronized" pattern, generally in the beta range $(13-30 \mathrm{~Hz})$.

The mean values for the eight experimental conditions suggested that the NEA was a frequency-sensitive device and that further analysis was needed.

A second analysis of data from Experiment I was computed in the form of an analysis of variance for a $2 \times 2 \times 2$ factorial design with repeated measures. None of the main effects or actions were significant. Since the presence or absence of any of the experimental conditions had no statistical significance, or significant effect on the NEA measure, it was concluded that the NEA was not measuring VEPs, but rather background EEG frequency. Based on these findings, Experiments II and III were conducted under the experimental conditions of: eyes open, stimulus light off, and no attending task.

\section{EXPERIMENT II}

\section{Method}

Subjects. Experiment II Ss consisted of 20 females between the ages of 21 and 27 years, who were part of a dental assistants class engaged in their senior year practicum. anticipated with such a group, there was a sharp curtailment of below-average scores. Nevertheless, there was sufficient spread from average, upward, to conduct a pilot study to ascertain whether a relationship exists between the NEA measure and IQ. This was the purpose of Experiment II.

Procedure. The procedure for collecting the NEA data was identical with that employed in Experiment $I$, under the experimental conditions: eyes open, flashing stimulus light off, and no auditory attending task. In addition, each $S$ was tested individually, with the Weschsler Adult Intelligence Scale (WAIS), by one of the investigators who was skilled in administering the test. A different investigator obtained the NEA data, and neither of the two investigators had any knowledge of the results obtained by the other until all subjects were run through both testing procedures. The distribution of the WAIS verbal IQ scores is given in Fig. 1.

\section{Results and Conclusions}

Correlational analyses were performed to determine the relationship between the NEA final score and the WAIS verbal, performance, and full-scale scores and each subscale score. Inspection of the correlation coefficients (Table 3) reveals a statistically significant inverse correlation between the NEA score and the WAIS. It was concluded that an inverse relationship exists between NEA scores and WAIS IQ scores for at least the upper half of the distribution of WAIS IQ scores. The extent of this relationship, however, is too low to warrant the use of NEA scores as an acceptable substitute for psychometric measures of human intelligence.

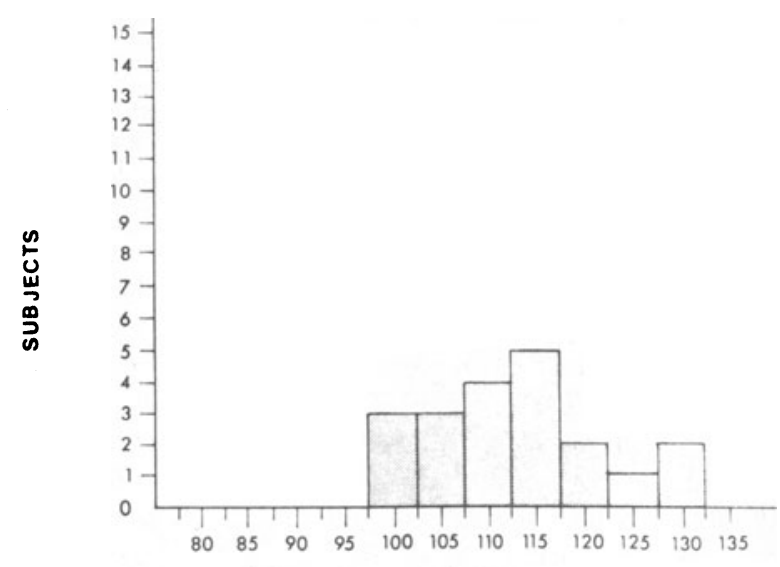

VERBAL IO SCORES

Fig. 1. Experiment II verbal IQ scores as measured by the Wechsler Adult Intelligence Scale $(\mathbf{N}=\mathbf{2 0})$. 
Table 3

Experiment II Showing Correlation Coefficients Computed Between NEA (x) Scores and All Scales and Subscales of the WAIS (y) $(N=20)$

\begin{tabular}{lll}
\hline WAIS Scale & $\Gamma_{\mathbf{x y}}$ & \multicolumn{1}{c}{$\mathrm{p}$} \\
\hline Verbal & $-.50^{*}$ & $\mathrm{p}<.025$ \\
Performance & -.14 & $\mathrm{n} . \mathrm{s}$. \\
Full & $-.43^{*}$ & $\mathrm{p}<.05$ \\
Information & -.23 & $\mathrm{n} . \mathrm{s}$. \\
Comprehension & $-.41^{*}$ & $\mathrm{p}<.05$ \\
Arithmetic & +.23 & $\mathrm{n} . \mathrm{s}$. \\
Similarities & -.20 & n.s. \\
Digit Span & .003 & n.s. \\
Vocabulary & $-.37^{*}$ & $\mathrm{p}<.05$ \\
Digit Symbol & $+.54^{*}$ & $\mathrm{p}<.01$ \\
Picture Completion & -.15 & $\mathrm{n} . \mathrm{s}$. \\
Block Design & +.11 & n.s. \\
Picture Arrangement & +.15 & n.s. \\
Object Assembly & -.15 & n.s. \\
\hline
\end{tabular}

$*=p<$ or greater

\section{EXPERIMENT III}

\section{Method}

Subjects. This final study was conducted in an effort to confirm the findings of Experiment II using a sample more representative of the normal population. Ss consisted of 50 hospital employees drawn from a pool of volunteers. They ranged in age from 18 to 63 years and in formal education from 8 to 16 years. Three Ss were lost through attrition, leaving a total of 47 . The final sample consisted of 25 males and 22 females. Eight of the Ss were black and 39 were white. The distribution of WAIS verbal IQ scores is given in Fig. 2.

Procedure. The experimental procedure was identical with that employed in Experiment II except that only the verbal portion of the WAIS was administered.

\section{Results and Conclusions}

A Pearson correlation coefficient of -.31 was obtained between NEA scores and the corresponding WAIS verbal IQ scores, which was significant at the .025 level. This was the same level of significance found in Experiment II, and it substantiates the conclusions drawn from that study.

\section{DISCUSSION}

The data indicate that the NEA was sampling and measuring the continuous, spontaneous, electrical activity of the brain. No statistically significant differences in NEA scores were found as a function of the presence or absence of a flashing light or when responding or not responding to an auditory stimulus. The results do show that whatever neuroelectrical parameters the NEA was measuring, it measured consistently across Ss. These findings indicated that it is unnecessary to present a flashing light stimulus to the Ss since the NEA appears not to be measuring visual averaged evoked potentials.

This study provides evidence for the existence of an inverse relationship between NEA scores and intelligence, as measured by the WAIS (full-.43, $\mathrm{p}<.05$ ), even though the NEA apparently is averaging spontaneous EEG frequency rather than VEPs. The negative relationship between NEA scores and IQ is in the predicted direction, based on Ertl's (1968) earlier findings. The relationship seems to be greatest for the composite verbal scale score $(-.50, \mathrm{p}<.025)$, and subtests comprehension $(-.41, \mathrm{p}<.05)$ and vocabulary $(-.37, \mathrm{p}<.05)$. Interestingly, scores obtained on the digit symbol subtest were positively correlated (+.54) with NEA scores, suggesting that NEA scores may be positively related to scores on tasks involving memory and visual motor speed.

As with the NEA scores, the question of what the WAIS subtests actually measure is in doubt. Factorial studies of Wechsler subtests indicate that about half of the true variance can be accounted for by a general factor. The remainder of the variance is attributed to such group factors as verbal performance or short-term memory (Cohen, 1959; Baumeister \& Bartlett, 1962a, b). Using the conceptualization, it is of interest to note that all of the major subtests loading on the verbal group factor, i.e., comprehension, similarities, and vocabulary, display inverse correlations with NEA scores. The subtests loading on short-term memory, i.e., digit-span, digit-symbol, and arithmetic, display either zero or positive correlations, while performance scales display either low negative or low positive, nonsignificant correlations. These data suggest that the psychometric factors involved with the NEA scores were verbal in nature.

To test the hypothesis that verbal psychometric factors are primarily responsible for the inverse relation between general IQ and NEA scores, Experiment III was conducted using only the verbal WAIS score. The correlation, though lower in absolute numerical value $(-.31)$ than those obtained between general IQ and NEA scores $(-.43)$, reached the same level of statistical

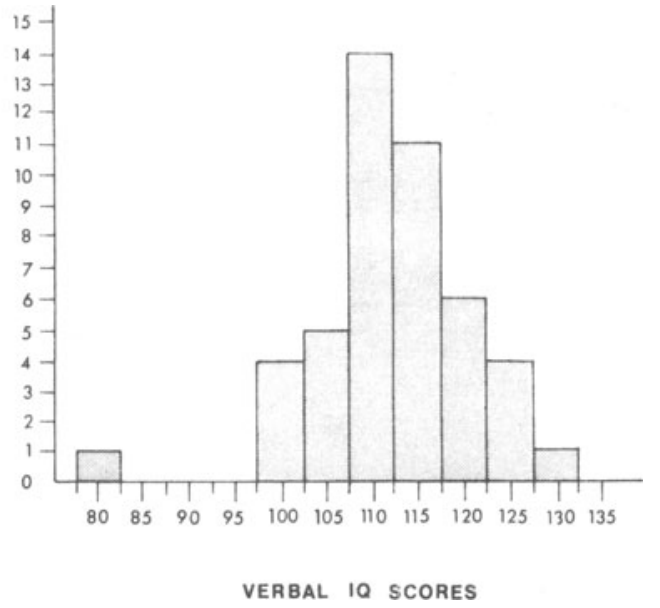

Fig. 2. Experiment III verbal IQ scores as measured by the Wechsler Adult Intelligence Scale $(\mathbf{N}=47)$. 
significance $(\mathrm{p}<.025)$. However, the correlation with verbal IQ accounts for only about $10 \%$ of the variance $(-.31)^{2}$, whereas the correlation with general IQ accounts for about $18 \%$ of the variance $(-.43)^{2}$. In neither case is the variance accounted for high enough to justify predicting either verbal or general IQs from NEA scores.

Conclusions drawn from the data are: (1) the NEA does not measure VEPs, but rather it is sensitive to the frequency of ongoing, spontaneous activity; (2) there is an inverse relationship between scores obtained with the NEA and psychometric verbal intelligence as measured by the WAIS, but the variance accounted for by the correlation is not sufficiently great to justify use of the NEA for predicting psychometric IQ.

\section{REFERENCES}

Asher, J. John Ertl's neural efficiency analyzer-bias-free test, or just a 'neat gadget'? APA Monitor, 1973, 4, 3, 1 and 8 .

APA Monitor. Published by the American Psychological Association, Washington, D.C. Vol. 4, No. 5, 1973.

Barry, W. M., \& Ertl, J. P. Brain waves and human intelligence. In F. B. Davis (Ed.), Modern educational developments: Another look. New York: Educational Records Bureau, 1965.

Baumeister, A. A., \& Bartlett, C. J. A comparison of the factor structure of normals and retardates on the WISC. American Journal of Mental Deficiency, 1962, 66, 641-646.

Baumeister, A. A., \& Bartlett, C. J. Further factorial investigation of WISC performance of mental defectives. American Journal of Mental Deficiency, 1962, 67, 257-261.

Caton, R. The electric currents of the brain. British Medical Journal, 1875, 2, 278.

Chalke, F. C., \& Ertl, J. P. Evoked potentials and intelligence. Life Sciences, 1965, 4; 1319-1322.

Cohen, J. S. The factorial structure of the WISC at ages 7-6, 10-6, and 13-6. Journal of Consulting Psychology, 1959, 23, 285-299.
Cromwell, L., Weibell, F. J., Pfeiffer, E. A., \& Usselman, L. B. Biomedical instrumentation and measurements. Englewood Cliffs, N.J: Prentice-Hall, 1973.

Ellingson, R. J. Relationship between EEG and test intelligence: A commentary. Psy chological Bulletin, 1966, 65, 91-98.

Ertl, J. P. Evoked potentials, neural efficiency and IQ. Paper presented at International Symposium for Biocybernetics, Washington, D.C., 1968.

Ertl, J. P. Fourier analysis of evoked potentials and human intelligence. Nature, 1971, 230, 525-526.

Kiloh, L. G., \& Osselton, J. W. Clinical electroencephalography. London: Butterworth, 1964.

Perry, N. W., \& Childers, D. G. The human visual evoked response. Springfield, Ill: Charles C. Thomas, 1969.

Plum, A. Visual evoked responses: Their relationship to intelligence. Unpublished doctoral dissertation, University of Florida, 1968.

Regan, D. Evoked potentials in psychology, sensory physiology and clinical medicine. New Y ork: Wiley-Interscience, 1972.

Rhodes, L. E., Dustman, R. E., \& Beck, E. C. The visual evoked response: $A$ comparison of bright and dull children. Electroencephalography \& Clinical Neurophysiology, 1969, 27, 364-372.

Shagass, C., Haseth, K., Callaway, E., \& Jones, R. EEG-evoked response relationships and perceptual performance. Life Sciences, 1968, 7, 1082-1091.

Shucard, D. W. Relationships among measures of the cortical evoked potential and abilities comprising human intelligence. Unpublished doctoral dissertation, University of Denver, 1969.

Shucard, D. W., \& Horn, J. L. Evoked cortical potentials and measurement of human abilities. Journal of Comparative \& Physiological Psychology, 1972, 78, 59-68.

Vaughan, H. G., Jr. New physiological approaches to psychopathology. In M. L. Kietzman, S. Sutton, and J. Zubin (Eds.), Experimental approaches to psychopathology. New York: A cademic Press, in press.

Vogel, W., Broverman, D. M., \& Klaiber, E. L. EEG and mental abilities. Electroencephalography \& Clinical Neurophysiology, 1968, 23, 166-175.

Weinberg, $H$. Correlation of frequency spectra of averaged visual evoked potentials with verbal intelligence. Nature, 1969, 224, 813-815.

(Received for publication June 6, 1973; revision received April 9, 1974.) 